\title{
L'economia a Borriana: anàlisi de la situació actual i perspectives de futur
}

\author{
Dolors TraVER TORRES (dtraver@atlcapital.es) \\ atl Capital A.V.
}

Avui més que mai, no es pot parlar d'economia d'un país o d'una regió, sense ser conscients de la situació econòmica global. Ací a Borriana ho sabem bé, fa dècades que som un poble exportador. L'economia local ha estat globalitzada des d'abans d'emprar aquest terme.

L'economia és cíclica, però els cicles econòmics poden ser molt diferents: més o menys acusats, més llargs, més curts... per això és molt complexa la realització d'anàlisis sobre la durada o la intensitat $i$ les conseqüències que pot provocar una crisi. En els últims anys estem enfrontant-nos a un cicle econòmic extremadament acusat; hem passat d'uns anys de molta bonança a una crisi que tothom compara a la del 1929.

El motiu: la globalització. Estem patint els efectes d'una situació que va començar per un problema local, als Estats Units el 2007 i que ací, a Europa i a l'Estat Espanyol, els nostres polítics i economistes es van cansar de repetir que pràcticament no ens afectaria, que el nostre sistema financer era molt més sòlid, que el nostre creixement era imparable. Sis anys després, mentre Estats Units es troba creixent a taxes superiors al 2\%, ací estem encara lluny d'eixir del pou.

La situació de l'economia espanyola segueix sent molt complexa; les últimes setmanes ens pronostiquen constantment que estem eixint del forat, que la prima de risc continua baixant, que ja estem al voltant de 180 punts bàsics (una prima de risc de 180 punts vol dir que paguem un 1,8\% més que Alemanya per demanar diners prestats a 10 anys), que la borsa puja i l'Ibex és un dels mercats més recomanats per tots els analistes, que el sistema financer espanyol no necessitarà un nou rescat per part d'Europa (després de demanar una línia de crèdit de 100.000 milions d'euros). Però encara que aquestes dades són positives, la veritat és que el deute de l'Estat Espanyol ja es troba al voltant del 100\% del PIB, que encara que el creixement econòmic millora, no ho farà tant com per a crear ocupació, de manera sostinguda, fins molt de temps; per tant, seguirem amb uns nivells d'atur dramàtics i difícilment podrem complir l'objectiu de dèficit marcat per Europa.

Si la situació espanyola és complicada, la situació de l'economia valenciana ho és més encara. Hem passat de ser una de les economies més fortes de l'Estat, a una situació totalment contrària.

Les dades macroeconòmiques no són positives; el dèficit del País Valencià, en tancar 2012, ha estat del 3,45\% (doblant l'objectiu anual de 1'1,5\%). Gràcies a projectes desmesurats i inútils. Projectes, que a més de costar molts milions d'euros, segueixen comptabilitzant unes despeses sagnants per al seu manteniment. Estem patint una privatització massiva de serveis, només comparable a la de comunitats com Madrid o Castilla-La Mancha. Una de les ferramentes més importants per a una economia com és un sistema financer sòlid ha desaparegut. Hem 
passat de tenir dues de les caixes d'estalvis més potents de tot l'Estat, un banc valencià i un sistema de cooperatives de crèdit locals, que s'estudiava a les facultats d'economia, a no tenir pràcticament res. Hem passat de lluir un sector constructor i immobiliari potent, a sofrir la sobreexposició a aquest sector, a patir les baixades de preus immobiliaris més grans de l'Estat i tragar-nos un estoc de vivendes que ens costarà molts anys netejar.

L'economia local ha evolucionat, des de finals del segle XIX, d'una manera ben diferenciada de la resta de l'Estat Espanyol, i Borriana, amb la zona litoral valenciana en general, acusa aquestes diferencies d'una manera encara més destacada. Mentre la resta de l'Estat basava la seua economia, al llarg d'aquesta època, en agricultura intensiva en treball i (deixant de costat casos molt concrets com el País Basc i Catalunya), la indústria era pràcticament insignificant, l'economia borrianenca i la valenciana, en general, comptaven amb un dinamisme remarcable. En aquests anys, l'agricultura valenciana començava una revolució, que va ajudar a potenciar la resta de sectors i que va guiar l'evolució de la nostra situació econòmica. Es tractava d'una agricultura intensiva, amb una modernització incipient i una vocació clarament exportadora, a més, acompanyada en algunes regions, d'una industrialització més avançada. Evidentment l'economia local ha viscut molt influenciada per aquesta situació i, en molts aspectes, ha continuat cometent les mateixes equivocacions, el monocultiu entre altres.

Per tal de realitzar una anàlisi completa de la situació, cal concretar l'evolució dels diferents sectors econòmics.

\section{Sector primari}

La importància del sector agrari al nostre poble no es pot sintetitzar en simples dades, com afirmen nombrosos autors; és quasi més important el factor social i l'efecte multiplicador del cultiu de la taronja que els efectes econòmics quantitatius.

El sector primari del litoral valencià ha tingut unes característiques molt particulars, que difícilment es troben a d'altres comarques valencianes o a l'Estat Espanyol. Aquestes característiques, que nosaltres hem assumit com a normals, han marcat clarament l'evolució econòmica del nostre poble.

El minifundisme, l'agricultura a temps parcial i el caràcter exportador, són senyes molt clares de la nostra agricultura. El pes de l'agricultura ha anat minvant al País Valencià en les últimes dècades. Aquest descens és molt més acusat si es tenen en compte dades quantitatives, però no s'ha de deixar de costat el grandíssim impacte social que ha tingut i té aquest sector, concretament el cultiu de la taronja al nostre poble: explotacions minifundistes, agricultura principalment a temps parcial, envelliment de la població... Són algunes de les característiques que han marcat l'evolució del sector primari al nostre entorn, sector que s'ha convertit en un efecte multiplicador que hem gaudit durant algunes dècades gràcies a la bonança d'aquest cultiu.

Un altre efecte, que pot considerar-se el més important per a l'economia local, ha estat l'efecte compensador, o estabilitzador, per a tots els cicles econòmics dels darrers cent cinquanta anys, fent possible que, en moments de crisi, la societat borrianenca poguera patir amb menys intensitat els moments crítics. Aquest és l'origen de la dita "el Levante feliz", tan denigrada en l'actualitat. 
Com hem dit, ha estat un cultiu clarament afectat pel minifundisme, que encara que presenta desavantatges clars, ha fet possible, junt a la dedicació a temps parcial, que gairebé totes les famílies comptaren, durant molts anys, amb uns ingressos extraordinaris que han propiciat un desenvolupament del comerç local i un major nivell d'estudis de la població, en comparació amb altres regions de l'Estat.

Però, en l'actualitat, i després d'haver viscut al llarg dels anys la decadència del cultiu de la taronja, el model que va funcionar en segles passats, amb mà d'obra barata i amb un producte de qualitat, ja no és competitiu en un món global.

És evident que el plantejament ha de canviar per a adaptar-se als nous temps globalitzats. La globalització, que en uns primers moments ens va venir molt bé i que van aprofitar molts exportadors borrianencs, se'ns ha tornat en contra.

Segons la teoria econòmica, només hi ha dues maneres de garantir l'èxit d'un negoci en un panorama competitiu com l'actual: mitjançant la competència en preus o buscant la diferenciació en qualitat.

El primer model ens va funcionar bé molt de temps, però hem pogut comprovar que a hores d'ara està desfasat, donat que, a la resta del món, hi podem trobar moltes economies en vies de desenvolupament, contra les quals no podem ni devem competir; encara que, amb les noves reformes econòmiques del govern central i amb l'abaratiment de costos laborals, potser torne a ser un model d'èxit. Evidentment, aquest no hauria de ser mai l'objectiu per a poder fer reviscolar l'agricultura local, ja que es tractaria de tornar als plantejaments propis d'una societat en vies de desenvolupament, situació que ja hauríem d'haver superat definitivament.

El segon model es basaria en la conscienciació de posseir un producte de millor qualitat, model que ens pot obrir la porta a un futur per als nostres cítrics. Únicament cal menjar-se una taronja a Madrid per a saber-ho.

Òbviament, una inversió és, com tot allò que suposa un canvi, una decisió arriscada, que necessita molt de temps i també recursos, especialment en la situació econòmica actual. Una acció semblant ja s'havia realitzat a Borriana en altres èpoques. Els llauradors, normalment amb explotacions agràries reduïdes, quan obtenien beneficis de les collites no van tenir por a reinvertir els diners en el conreu de la taronja, ampliant els seus horts i modernitzant-los, situació que ha estat indirectament una de les causes de la manca d'indústria, no vinculada al sector agrari.

Tenint en compte la valentia d'aquests xicotets productors, és sorprenent que actualment coste tantíssim apostar per un negoci en què comptem amb una experiència tan extensa i amb una qualitat productiva tan elevada. És evident que la situació econòmica no és la més apropiada, però és en aquests moments quan sorgeixen les oportunitats d'inversió més atractives i, normalment, quan més rendibilitat es pot obtenir a llarg termini.

Una de les alternatives més interessant, tenint el compte la distribució de la propietat de la nostra agricultura, seria potenciar el cooperativisme de nou; amb una bona gestió i una estratègia definida podem repetir l'èxit que ha tingut aquesta fórmula en altres regions.

Des de les institucions que tenen algun poder decisori al respecte, s'hauria d'incentivar i afavorir un canvi en l'estratègia, per a poder orientar i ajudar els agricultors, recolzant la coordinació entre els diversos actors implicats, potenciant accions orientades a la millora de la difusió del producte fora de les nostres terres i creant una imatge de marca, per tal de reactivar un sector tan important en el nostre passat i que podria convertir-se, amb la unió dels estaments, en un sector amb evidents possibilitats de futur. 


\section{Sector industrial}

El sector industrial valencià, en particular, i el de l'Estat Espanyol, en general, mai van tenir una revolució industrial tan profunda com la que van experimentar altres països europeus, amb fortes entrades de capital estranger i amb un desenvolupament d'un sector o alguns sectors en concret, condicions necessàries per a aconseguir que l'economia completara la revolució industrial amb garanties d'èxit.

A les nostres terres, es va tractar d'una evolució més tranquil·la, ja que no vam poder comptar amb un sector industrial fort que actuara com a dinamitzador, $\mathrm{i}$ les inversions estrangeres que arribaven al nostre Estat es concentraren bàsicament en territoris de fora del País Valencià. Només algunes localitats molt concretes, com per exemple Alcoi o Ibi, van tenir i mantenen a hores d'ara una estructura industrial més sòlida. Més que d'indústria, com afirma Ernest Lluch a La via valenciana, es podria parlar que al País Valencià l'artesania es va professionalitzar i van sorgir xicotetes indústries al voltant de nuclis familiars molt localitzats.

Al cas concret de Borriana, com hem comentat abans, els esforços es van centrar en l'agricultura, sense capital foraster potent i amb un negoci rendible, com era el cultiu de la taronja. Els fluxos dels beneficis que es produïen es dedicaven bàsicament a reinversió en el propi sector, que, marcat pel minifundisme, tampoc generava una concentració de capital suficientment forta com per a tirar endavant el sector industrial que, en conseqüència, no va resultar significativament important en aquella època.

A pesar dels avenços i de l'evolució de la societat en el darrer segle, pel que fa al sector industrial a Borriana, no s'ha seguit el ritme d'altres localitats similars, ja que la major part de les persones que treballen en aquest sector ho fan fora de la ciutat. És necessari remarcar que un sector industrial potent és bàsic per a qualsevol economia, fins i tot si es tracta d'una xicoteta economia local, pels fluxos de capital i l'ocupació que pot generar. Per això és indubtable que s'hauria de realitzar un gran esforç en aquest sentit i, més encara, en una situació econòmica com l'actual, en què estan produint-se contínuament canvis significatius en la manera d'entendre la industrialització. Desprès dels últims anys marcats per la deslocalització de la indústria cap a països amb costos laborals més baixos, sobretot països emergents, l'increment dels seus salaris i la reducció dels nostres, estem constatant que grans multinacionals comencen a considerar que es poden obtenir més beneficis a països com el nostre, on els costos laborals continuen sent un poc més elevats, però que compten amb una mà d'obra més qualificada, a més d'una seguretat jurídica major. Aquesta situació està començant a produir efectes positius en molts pobles espanyols, que se n'estan beneficiant, per exemple a Ubrique, on es fabriquen gran part dels productes de marroquineria de Chanel, Carolina Herrera i Dior, i a Ibi, on s'ha recuperat la producció de Moltó, Injusa i Famosa.

Està donant-se també el cas que empreses que s'havien establert a alguns països en vies de desenvolupament, com Xina o Índia, han retornat, amb la intenció d'incrementar la productivitat, la qualitat $\mathrm{i}$, en consequiència, els beneficis.

A Borriana, el pes del sector industrial dins del PIB es pot considerar limitat. Únicament tenim xicotetes indústries que concentren una quantitat de treballadors molt reduïda. Les indústries borrianenques solen ser familiars; tenim exemples d’indústria joiera, de 
marroquineria i sobretot lligada al sector agrari, amb equips directius amb molts anys d'experiència al sector i mà d'obra molt qualificada que hauria de ser aprofitada al màxim de les seues possibilitats.

Com ja hem dit, molt ciutadans borrianencs treballen al sector industrial, però la majoria ho fa fora de la nostra ciutat, en localitats veïnes que van ser molt més àgils a l'hora d'industrialitzar les seues economies.

Tenint en compte que no es tracta del sector més significatiu en l'economia local, hauríem de poder aconseguir que tots els esforços, tant d'institucions públiques implicades com de les pròpies empreses, es concentraren a potenciar i publicitar les experiències de les indústries ja existents, per tal d'afavorir la creació de noves empreses.

\section{Sector serveis}

Les economies avançades han sofert, en el segle passat, un procés de millora del nivell de vida generalitzat que, normalment, ha vingut acompanyat per un canvi de l'estructura productiva, passant de ser economies fonamentalment agràries o industrials a economies basades en la prestació de serveis.

Tant a l'Estat Espanyol com al País Valencià, el pes d'aquest sector supera actualment el $60 \%$ del PIB. És per això que s'ha de prestar especial atenció a l'estudi i evolució d'aquest sector, que agrupa moltes activitat diferents, però que en l'economia local es concentra bàsicament en el comerç, donat que, degut també a la situació econòmica actual, d'altres activitats, com els serveis immobiliaris, han deixat de tenir la importància i el volum de negoci d'anys anteriors.

El comerç és una peça fonamental de l'economia de Borriana; tot i això hem de tenir en compte que, en les darreres dècades, aquesta activitat ha sofert canvis importants. De ser una localitat de referència per a poblacions veïnes, els nostres comerciants han anat patint una reducció considerable i continuada del clients. L'obertura de grans centres comercials, a Castelló i a València fonamentalment, i les ampliacions d'horaris comercials, han suposat una transformació profunda en àmbits significatius d'aquest sector, com són l'oferta i la demanda dels consumidors.

Per part de la demanda, com a clients, ens hem acostumat a comprar en diumenge, per Internet, amb descomptes fora de temporada de rebaixes... i per part de l'oferta, el repte per als comerços tradicionals està sent molt important. És evident la pèrdua de la quota comercial que ha suposat l'entrada de grans superfícies i la necessitat d'incrementar la productivitat del xicotet comerç.

Per a intentar dinamitzar el comerç local, la primera iniciativa hauria d'anar encaminada a la unificació de criteris i, conseqüentment, a la unitat dels comerciants. L'associacionisme és un factor fonamental en la manera d'entendre i millorar la situació actual del comerç local, per a poder caminar tots en la mateixa direcció.

La dinamització del comerç local es pot aconseguir de diverses maneres: professionalització, proximitat, qualitat, especialització... i, sobretot, l'associacionisme, però associacionisme de veritat. A Borriana han arribat a existir fins a 14 associacions de comerciants; és molt positiu que cada barri vulga potenciar els seus comerços propis i tenir iniciatives diferenciades, però és molt necessària la unió de tots els comerços, la 
coordinació de les activitats que es proposen, per a poder permetre un estalvi de costos promocionals important per als comerços.

Des de les institucions, juntament amb els comerciants, seria fonamental seguir una línia definida d'actuació que permetera actuar amb la finalitat d'aconseguir uns objectius comuns, concrets i realistes, que pogueren reactivar el comerç local. No és suficient amb realitzar campanyes esporàdiques i ubicades en zones reduïdes (especialment al centre de Borriana), deixant la resta de comerciants de la localitat sense activitats promocionals. Aquesta és, entre d'altres, una de les causes de la manca d'unió entre tots els comerciants, que ha provocat la seua dispersió i que els esforços realitzats no hagen obtingut el resultat desitjat.

També es podrien fer accions comercials concretes en determinats moments de l'any en què la demanda es més forta, per exemple en les setmanes pròximes a actes fallers, que suposen un impuls fort per a alguns sectors del comerç local i que, encara que en els últims anys estem veient iniciatives de tot tipus, molt imaginatives per part dels comerciants, s'hauria d'aprofitar molt més l'increment de demanda i les possibilitats de negoci que genera el poble.

\section{Sector turístic}

El sector turístic, juntament amb el de l'agricultura, pot ser el que més debat ha generat des de sempre al nostre poble, i una de les causes evidents és que es tracta del sector que compta amb més recursos naturals per explotar. Les possibilitats que té Borriana en aquest camp són grandíssimes, i els recursos (la platja i el clima principalment) també ho són.

Una vegada especificat açò, tots podem constatar que les dificultats i les divergències es produeixen en parlar de les diferents posicions respecte de la potenciació del turisme i l'explotació d'aquests recursos. La primera evidència d'aquests plantejaments és que ja s'han perdut massa anys, i fins i tot dècades, debatent aquestes qüestions.

Si realitzem una comparativa amb localitats del nostre entorn, podem comprovar que les diferències són evidents, començant per la qualitat i la quantitat dels recursos naturals que posseeixen.

Durant massa temps, no hem tingut una preocupació de potenciar el turisme, a causa sobretot de l'existència d'altres fonts d'ingressos, entre el quals cal remarcar la taronja, que feien que ens poguérem permetre aquesta despreocupació. Però les circumstàncies han canviat en les últimes dècades, especialment als darrers anys. Gràcies a esdeveniments molt concrets, com l'Arenal Sound, pareix que estem començant a despertar.

Evidentment, un tema molt important de què cal parlar quan ens referim al turisme i l'economia local és l'Arenal Sound. Les implicacions que comporta són, de moment, uns efectes a curt termini, tot i que podrien convertir-se en beneficis a llarg termini si es realitzaren les actuacions adequades, sempre parlant del punt de vista turístic i econòmic. $\mathrm{A}$ curt termini l'impacte és ben clar i, encara que, com tots els esdeveniments que impliquen una assistència massiva de públic, provoca unes situacions problemàtiques per als veïns del poble (especialment els de les zones marítimes), l'impacte econòmic que suposa per a moltes famílies és molt important, sobretot en el context actual. 
A més de les conseqüències a curt termini, es podrien considerar molt més importants els avantatges que podria arribar a aconseguir a llarg termini. A l'estiu de 2012 (encara no hi ha dades oficials de l'últim festival), van estar a Borriana al voltant de 50.000 persones, amb unes despeses mitjanes de 409 euros per persona. Però, el més important és que el $77 \%$ dels assistents tenen entre 19 i 30 anys, i un $81 \%$ amb estudis superiors que, com a mínim, van conèixer Borriana, van gaudir de la nostra platja, del nostre clima i que hauríem de poder considerar com a potencials visitants i/o futurs residents a l'estiu. Ells i les persones a qui conten que han estat al nostre poble. Aquest es el potencial impacte que hem de cuidar i que pot suposar un canvi molt important per al sector en els pròxims anys.

El principal problema que trobem al turisme a Borriana és que la gent no es plantejava estiuejar a la nostra localitat, la majoria perquè, a pesar de l'assistència a diverses fires de turisme, el nostre no era un destí turístic prou conegut fora de certs àmbits massa reduïts. Hauria de fer-se una planificació des de totes les instàncies implicades, per tal de poder aprofitar el paper que està efectuant aquest esdeveniment en un aspecte tan significatiu. Una vegada consolidat tot açò, hauria de concretar-se la segona qüestió: són suficients les infraestructures, amb que compta Borriana, per a poder acollir la gran quantitat de persones que es concentren en unes poques jornades? La resposta en l'actualitat no és suficientment positiva. A més de les necessitats bàsiques, que haurien de ser ateses per a poder donar servei, amb una mínima dignitat. Les places hoteleres són pràcticament inexistents, la platja està exactament igual que fa dècades, costa trobar el telèfon d'un restaurant a Internet, les places d'aparcament són bastant limitades, els accessos a la zona marítima estan desfasats i les activitats d'oci que s'ofereixen també són escasses. No podem anar per darrere dels fets: primer s'ha de fer l'oferta i després vindrà la demanda. Si comencem la casa per la teulada, cosa que sembla que és el que està passant, no podrem aprofitar totes aquestes possibilitats de futur en l'àmbit turístic. Tenim la sort de tenir uns recursos naturals immillorables i una potencial demanda. Mitjançant el festival, a més d'altres possibles actuacions, el que hem d'aconseguir és fer coincidir en els mateixos interessos l'oferta i la demanda per a poder arribar a ser més atractius per al turisme.

Podríem concloure que, tenint en compte que gaudim de moltes possibilitats, per ser un destí turístic atractiu, a més d'estar ubicats en un país desenvolupat, sense conflictes destacats i amb una bona comunicació, tant per als turistes nacionals com per als internacionals, hauríem de demanar a les institucions corresponents una predisposició positiva per a poder aprofitar tots els avantatges $i$, en consequiència, poder fer coincidir els interessos del borrianencs amb els dels futurs forasters que vingueren a passar les seues vacances a Borriana.

Després d'aquestes reflexions, i per tal de concloure amb una valoració positiva, es pot afirmar que les possibilitats per a millorar el futur econòmic de Borriana són abundants. Si parlem de recursos naturals o d'experiència o, fins i tot, del caràcter decidit dels nostres conciutadans, entre d'altres consideracions, l'evidència ens confirma com un poble líder al llarg de la nostra història, especialment al segle passat.

Tenim moltes possibilitats, persones i joves molt preparats que poden aportar moltíssim, sobretot iniciativa i innovació, molt necessitada actualment per a canviar la situació. Les institucions estan estancades, les accions que s'emprenen són les mateixes tots els anys, les persones les mateixes, no s’incentiva la innovació ni els emprenedors locals. Amb 
la conjuntura tant precària que patim actualment és necessari una reorganització de les despeses públiques, de la dimensió de les nostres institucions i l'aprofitament més eficient dels recursos.

L'actualitat ens ha fet canviar uns plantejaments que, fins fa poc de temps, eren prioritaris. La situació és, ara, la inversa. De tota manera, i a pesar de les condicions adverses, hem de valorar el moment actual com una oportunitat per a demostrar que, com a borrianencs, hauríem de tornar a posar tot el nostre interès a fer un esforç per a portar endavant una remuntada.

\section{BIBLIOGRAFIA}

Soler, V. (2003): Economia espanyola i del País Valencià, València, Universitat de València.

Lluch, E. (2001): La via valenciana, Catarroja, Afers.

Deloitte (2012): Estimación del impacto económico del festival de música Arenal Sound, Borriana, Arenal Sound.

$<$ www.cincodias.com>.

$<w w w . e x p a n s i o n . c o m>$.

\section{BIONOTA}

\section{Dolors Traver Torres}

(Borriana, 1985) Economista per la Universitat de València (2008) i màster en finances per la Universitat d'Alcalá d'Henares (2009). Treballa com a assessora financera en l'agència de valors atl Capital des de 2009. Assessor Financer Europeu per EFPA Espanya i experta en valoració d'empreses per l'Institut d'Estudis Bursàtils de Madrid. Compagina aquesta activitat amb l'elaboració i presentació d'estudis de planificació financera en la mateixa entitat. 